\title{
O MARXISMO ANALÍTICO E A QUESTÃO DAS Classes SOCIAIS
}

\author{
Marcos Vinicius Pansardi
}

\section{I - INTRODUÇÃO: OS INDIVÍdUOS, AS Classes SOCIAIS E O MARXISMO}

O objetivo deste estudo é compreender o papel das classes sociais e da ação coletiva no pensamento dos autores que se inserem no chamado "marxismo analítico". Como sabemos, estes autores buscam uma aproximação entre as concep̧ões do individualismo metodológico com a teoria marxista, que é em essência uma teoria metodológica coletivista, o que, à primeira vista, pareceria ser uma contradição. Contudo, como veremos, o individualismo metodológico é visto como a solução para graves problemas a que a teoria da ação coletiva marxista induz, portanto, não haveria contradição e sim "complementação".

A grande questão não resolvida pelo marxismo é de como as classes sociais que podem ser deduzidas através das estruturas produtivas se definem como atores históricos reais. Já que é cada vez mais claro, nas sociedades modernas, que a simples tentativa de buscar classificações objetivas - por mais sofisticadas que sejam, por exemplo nos trabalhos de Eric Olin Wright - não explica o porquê da adesão, ou não, dos sujeitos individuais a um sujeito coletivo. 
O erro estaria na incapacidade do marxismo em explicar o comportamento individual, já que este não responde automaticamente a sua inserção estrutural: a questão essencial seria encontrar os mecanismos que traduzem esta inserção no comportamento individual. Como resumiria Przeworski: "A vinculação entre as relações sociais e o comportamento individual é o calcanhar de Aquiles do marxismo" (Przeworski, 1989, p. 113).

A origem do problema não estaria numa interpretação deturpada do marxismo - seja uma interpretação rudemente mecanicista (vulgar), seja numa interpretação estrutural sofisticada - e sim na própria base metodológica deste: seu ponto de partida analítico já se dá com a existência de um sujeito coletivo - a classe - e, contudo, esta pode ser ainda reduzida às suas dimensões individuais. $O$ problema não estaria em explicar o comportamento individual a partir das classes, mas sim em explicar as classes a partir do comportamento individual.

Os indivíduos têm escolhas, e pertencer a uma classe é uma escolha, que não pode ser reduzida a qualquer determinação estrutural. $O$ marxismo deve ser capaz de ir a um nível anterior na escala social e ser capaz de explicar as escolhas individuais, e esta é ainda uma tarefa por fazer.

Portanto, o individualismo metodológico que originalmente sustentava a economia política neo-clássica, e que não comportava a idéia de sujeitos coletivos intermediários entre o indivíduo e as instituições, passa a ser a soluçâo para um marxismo que busca revigorar o espaço para a ação subjetiva na história. Depois de décadas de domínio de explicações estrutural-funcionalistas que reduziam a ação consciente a uma determinação irresistível de "leis históricas", ou a reflexos de uma estrutura onisciente.

Assim, o marxismo analítico aponta para todo um programa de estudo que concebe a história como resultado de ações estratégicas de indivíduos que buscam a realização de objetivos pré-determinados: 
"Uma teoria econômica marxista - e por marxista não designo apenas os que aceitam as hipóteses de Marx ou mesmo os seus problemas, mas os que procuram compreender a relação entre conflitos e evoluções na busca da emancipação universal - deve ser uma teoria que incorpore no próprio cerne de suas hipóteses todo o conjunto de alternativas estratégicas. Deve ser uma teoria que dê aos agentes econômicos uma chance de organizar-se, lutar coletivamente, exercer influência sobre o Estado e produzir efeitos sobre a economia. Deve ser uma teoria que aborde as estruturas específicas do mercado capitalista, as formas específicas de organização das classes e do Estado e os padrões específicos de exploração e acumulação como consequências dependentes dos comportamentos estratégicos dos agentes empenhados na realização de seus objetivos, sob todas as formas que possa assumir esse empenho no âmbito do capitalismo" (Przeworski, 1989, p. 273).

Uma das mais nocivas conseqüências dessa abordagem marxista tradicional se reflete na incapacidade de compreender as características peculiares em que se desenvolve o conflito de classes em nossa época, ou seja, a capacidade que o sistema capitalista desenvolvido tem mostrado em incorporar e neutralizar o potencial revolucionário da classe trabalhadora. É apenas com a abordagem proporcionada pelo individualismo metodológico que se pode compreender que o conflito capital-trabalho não é necessariamente um "jogo soma-zero". Segundo Przeworski, a teoria marxista tradicional é "tosca, logicamente incorreta e empiricamente falsa" (Przeworski, 1988, p. 16).

A proposta dos marxistas analíticos é então a de renovar o marxismo, incorporar algumas das mais recentes contribuições da teoria social da século $\mathrm{XX}$, e retirando do marxismo inconvenientes heranças metafísicas proveniêntes do século XIX - entre as quais a análise dialética: ponto de origem do caráter teleológico que obscurantiza a teoria social marxista. 
O marxismo enquanto tentativa de explicar as características e as mudanças ocorridas na sociedade humana já teve seu valor aprovado pelo "tribunal da história", contudo precisa de um urgente rejuvenescimento. O sentimento que move o projeto dos marxistas analíticos é resumido por John Roemer na introdução do livro por ele organizado, destinado a apresentar as idéias do grupo:

“(...) reconhecer que a marxismo é uma ciência social que nasce durante o século XIX. Como tal está sujeito a certas limitações: é primitivo frente aos estandares modernos e resulta equivocado tanto em alguns detalhes como inclusive, talvez, em certos argumentos essenciais. Não obstante, seu poder para explicar certos períodos e fatos históricos parece ser tão forte que deixa a sensação de ter uma essência válida, mas que necessita ser esclarecida $c$ analisada. Não se abandona uma boa ferramenta porque não se pode utilizí-la em certas coisas, especialmente porque não se tem outra melhor" (Roemer, 1989, p. 10).

\section{II - A BUSCA DE FUNDAMENTOS: INDIVIDUALISMO METODOLÓGICO E ESCOLHA RACIONAL}

A tarefa proposta pelos autores é a de produzir novos fundamentos à teoria marxista, ou melhor, microfundamentos à teoria classista do marxismo. Estes microfundamentos estariam colocados à disposição do marxismo através das ferramentas do individualismo metodológico, que assim foi definido por Elster:

"Por individualismo metodológico entendo a doutrina de que todos os fenômenos sociais (sua estrutura e suas alterações) são, em princípio, explicáveis em termos de indivíduos - suas propriedades, objetivos e crenças" (Elster apud Przeworski, 1988, p. 21). 
O individualismo metodológico tem como fundamento a concepção de que as ações dos indivíduos são orientadas para a realização de objetivos racionais (teoria da escolha racional).

Przeworski enfatizaria que a declaração de Elster é estéril, se não fosse acrescentada ao fato de que o resultado de ações individuais (os fenômenos sociais) muitas vezes são indiretos, não antecipados, e as vezes indesejados por todos. Ou seja, as decisões são individuais, mas os resultados são um produto da confronto entre as partes.

As categorias do individualismo metodológico e da escolha racional são produtos da teoria economia neoclássica, e contudo o marxismo analítico sustenta haver diferenças qualitativas fundamentais no seu uso daquelas ferramentas. Segundo Roemer, haveria quatro pontos de diferenciação:

“(...) o marxismo sustenta: l) um compromisso pela maleabilidade das preferências humanas, pela formação social do indivíduo; 2) que a teoria econômica neoclássica do bem-estar é débil c errônea devido à formação autônoma das preferências; 3) a obrigação, baseada em uma certa leitura da história, de conceder importância à ação coletiva e ao poder no processo de solução; no particular, o poder de classe e a ação de classe mas, de modo mais geral, o poder nacionalista e possivelmente o poder religioso. $\mathrm{Na}$ teoria do equilíbrio competitivo ninguém tem nenhum poder; 4) a crença na injustiça do capitalismo e sua transitoriedade, que brotam da visão histórica do mundo, bascado na evolução das formas de propriedade" (Roemer, 1989b, p. 230).

As duas primeiras afirmações determinam um limite às preferências individuais. Ao contrário da economia neoclássica que compreende as opções individuais como autônomas, os marxistas analíticos entendem a tomada de decisões como produto de dois fatores: 1) os recursos (condições) disponíveis e, 2) os objetivos a serem alcançados; tanto um 
como outro podem ser determinados pela estrutura das relações sociais. Contudo, as restrições estruturais não ditam a última palavra sobre a escolha dos indivíduos, elas limitam seu campo de ação, no entanto, dentro destes limites os indivíduos realmente escolhem aquilo que acreditam ser o melhor caminho para atingir os objetivos estabelecidos anteriormente. A escolha, portanto, não é arbitrária, não é completamente independente, pois existe uma "estrutura de escolhas disponíveis aos agentes” (Przeworski, 1989, p. 18). Aqui os marxistas analíticos interpretam a relação entre ser e consciência social de uma maneira própria, não como uma determinação, ou minimamente como uma indução de comportamento, mas como uma restrição de escolhas. $O$ indivíduo não é conduzido pelas estruturas, estas não comandam suas escolhas, ele se mantém no comando, é racional e não um reflexo de estruturas racionais (Ibidem, p. 18). Não estamos em frente de uma visão estruturalista da consciência social, nem de uma concepção sobre normas sociais que internalizar-se-iam e determinariam um comportamento imposto pela . sociedade.

A objetividade das estruturas sociais se dá apenas por sua anterioriedade, como condição dada que se apresenta à ação dos homens, é sobre ela que se dá o conflito entre os homens ou classes. $O$ conflito pode mesmo se constituir sobre esta estrutura de escolhas, os homens podem decidir alterar as relações sociais. Perde força a idéia que o capitalismo cria consciências, determina padrões de comportamento e ação. $\mathrm{O}$ conceito de ideologia parece esvair-se, o homem conserva sua capacidade racional de escolher objetivos, há apenas limites e estes podem ser objetos de mudança, basta isto ser objeto de escolha dos indivíduos desta sociedade.

A ação do analista é assim compreender estas "estruturas de escolhas" e como estas limitam as escolhas, para além das dotações de recursos e os objetivos a serem alcançados. $O$ marxismo analítico não tem 
uma "psicologia materialista" que explique como, entre as escolhas permitidas pelas relações sociais, o indivíduo afinal escolhe uma e não outras disponíveis; portanto, não tem uma teoria sobre a formação endógena das preferências (Roemer, 1989b, p. 222). Ou seja, a escolha não é explicada e sim as "estruturas de escolhas".

A teoria marxista tradicional pensava na formação de preferências, e na formação das identidades e das classes como um produto definido pelos conflitos. Estas são transformadas continuamente - não há a idéia neoclássica de uma identidade imutável, atemporal -, isto é, são moldadas, destruídas e, novamente reconstruídas. Nesta concepção, os conflitos definem se determinada coisa é fonte de satisfação, se um objeto específico pode ser alcançado, se um determinado curso de ação é admissível (Przeworski, 1988, p. 9).

No entanto, os marxistas analíticos defendem a idéia de que as preferências se formam historicamente e as pessoas agem racionalmente com base nas preferências que têm e as quais não são contraditórias, como, aliás, vimos anteriormente (Ibidem, p. 10).

Além da análise das "estruturas de escolhas" o marxismo analítico tem uma ferramenta poderosa para compreender o resultado dos conflitos: as escolhas finais dos indivíduos racionais - após serem "selecionadas" as escolhas possíveis - podem ser desvendadas pela "teoria dos jogos". Segundo estes autores, a teoria dos jogos é, bem ou mal, a única teoria que pode dar conta de uma situação de conflito.

Numa situação de conflito os indivíduos escolhem racionalmente os objetivos que melhor se adequam aos recursos que dispõe. A busca de ganho na relação com outros indivíduos pode ser entendida de forma estrita ou abrangente, como nos explica Elster: "De forma estrita, ele é o benefício material recebido para cada ator. Em uma interpretação mais ampla, ele cobre tudo que tenha valor para a autor em cada situação, inclusive (possivelmente) os ganhos de outros autores" (Elster, 
1989, p. 183). As decisões são estratégicas, isto ć, são tomadas levando em consideraçĩo as decisões racionais dos outros indivíduos envolvidos no conflito. Por fim, a jogo tem geralmente um fim: no chamado "ponto de equilíbrio", um determinado resultado final em que a estratégia de cada ator é ótima vis-a-vis às dos outros.

Discutamos, agora a terceira diferença entre a teoria neoclássica e o marxismo analítico: a crença na importância da ação coletiva ou classista.

\section{III - CONDIÇÕES PARA A AÇÃO COLETIVA}

O primeiro texto importante de Przeworzki sobre as classes sociais é de 1977 - O Processo de Formação de Classes. Neste texto já encontramos presente a preocupação central dos marxistas analíticos quanto a conceito de classe, qual seja: a insatisfação com as definições objetivas que definem as classes pela sua posição no modo de produção.

Przeworski, contudo, não tem ainda o individualismo metodológico como explicação para suas inquietações. Este texto é muito interessante, pois, o autor incorpora e desenvolve criticamente as análises gramscianas sobre a questĩo da classe. sem deixar de incorporar pontos da visĩo de Poulantzas, Thompson e mesmo as críticas weberianas ao conceito marxista de classe social.

A resposta ì questia de como os atores coletivos se formam é buscada nos conflitos que emergem da sociedade. Como Thompson, para Przeworski as classes sĩo produtos das lutas sociais, as lutas de classes são anteriores à formação das classes.

Os conflitos se dão na sociedade entre os vários grupos sociais que buscam tanto alcançar seus objetivos como, principalmente, impor sua visão de mundo sobre toda a sociedade. O problema não é apenas 
teórico e sim prático: "é no campo da ideologia que as pessoas se tornam conscientes das relações sociais", frase de Marx que Przeworski incorpora, procura demonstrar que a formação das classes é um processo longo onde esta luta de classes ideológica é uma luta sobre as classes, antes de ser uma luta de classes. A luta da burguesia é manter o conflito na sociedade a nível individual, suas instituições negam a conflito classista, a política é vista como a busca universal do "bem-comum" e não como o conflito de classes com visões e interesses antagônicos.

Portanto, a classe nem é um epifenômeno, nem está livre de determinação, contudo, a luta de classe tem um efeito autônomo sobre a formação daquela. A objetividade das relações produtivas se dá ao nível de determinar quais os projetos historicamente definíveis podem ter viabilidade efetiva.

As pręocupações que levariam Przeworski a encontrar-se com o individualismo metodológico podem já ser encontradas em sua explicação da efetividade histórica das ideologias; pois, para Przeworski estas só podem ter efetividade - gerar uma identidade coletiva - se correspondem à maneira com que as pessoas (os indivíduos, eu diria - MVP) sentem a sua vida quotidiana. Aqui se esboça a ligação entre a identidade coletiva e a visão dos indivíduos.

Já se encontra neste ensaio a explicação - que seria central na análise posterior de Przeworski - do porquê a simples similariedade da posição de classe não leva à solidariedade: a resposta está na competição dos operários entre si, que só se silencia com a organização destes em classe.

Em estudo posterior $A$ social-democracia como fenômeno bistórico (1989) - Przeworski aplicaria estas idéias ao analisar o desenvolvimento histórico da social-democracia através do século XX. Aqui temos dois avanços importantes no caminho do individualismo metodológico: o primeiro, é a compreensão de que sob a capitalismo democrático o con- 
flito de classes não é necessariamente e irremediavelmente antagônico, portanto, que o compromisso entre-classes é possível, e é essa a característica do caminho social-democrata. Segundo, que a social-democracia, e o caminho que ela trilhou, foram uma escolha do proletariado, e não uma derrota para a burguesia ou uma imposição cega da história. A democracia eleitoral-representativa quebra a concepção classista tradicional do século XIX, esta recua a uma visão "ampliada" do trabalhador. Passa-se da visão de uma sociedade sem classes para a de uma sociedade de massas.

Incorporando o individualismo metodológico, Przeworski, se, por um lado, aceita a crítica salutar deste à teoria da ação coletiva do marxismo, por outro lado mostra uma relutância muito grande em assumir seus resultados. Przeworski lembra que, se fosse verdadeira, a teoria de Mancur Olson inviabilizaria qualquer ação coletiva, o que obviamente significa que esta teoria está incorreta.

As tentativas de vários autores em rebater e responder ao dilema do "carona" (free-rider), são mapeadas por Przeworski em seu texto Marxismo e escolba racional:

“1) o problema é irrelevante com base nos pressupostos do coletivismo metodológico (Holmstrom, Pizzorno). 2) As pessoas, os trabalhadores, ao menos, não são egoístas (Booth). 3) Os trabalhadores são coagidos com tal rigor por suas condições que não têm escolha: relativamente aos trabalhadores a abordagem da escolha racional coloca um falso problema (Roemer). 4) Os trabalhadores têm uma inclinação especial para alterar as preferências uns dos outros através da comunicação (Elster, Offe \& Wiesenthal). 5) Os trabalhadores satisfazem às condições para cooperação num dilema da prisioneiro interativo (Shubik. Taylor): estão repetidamente na mesma situação; não sabem durante quanto tempo permanecerão nessa situação; e têm um coeficiente baixo de preferência pelo presente (Edel, Shaw). 6) Os trabalhadores respondem às condições para uma alteração endógena de probabili-

Temáticas, Campinas, 3(5/6):139-164, jan./dez. 1995 
dades de sucesso; quando alguns deles dĩo início à ação coletiva, a probabilidade de sucesso da açĩo coletiva aumenta, o que significa que o benefício esperado também aumenta, sobrepujando o custo esperado para os traballadores adicionais, cuja participaçio, por sua vez, aumenta ainda mais a probabilidade de sucesso, e assim por diante" (Przeworski, 1988, p. 13).

Todos esses argumentos criticam a teoria de Olson partindo do princípio que a teoria correta deve partir de uma visão coletivista, que os trabalhadores em geral estão e se organizam em classe. Przeworski assume a essência da crítica de Olson: a organização do proletariado $\mathrm{cm}$ classe nĩo é tĩo evidente que nĩo precise ser explicada. As classe e a ação das classes sĩo fatos incomuns na história (mesmo do capitalismo); o proletariado em geral nĩo está organizado em classe, isto é verdade mesmo em períodos pretéritos da história do capitalismo.

Assumindo a própria crítica do individualismo metodológico, a pergunta certa deve ser essa: “(... ) sob que condições, de sempre a nunca, a solidariedade (cooperaçĩo de classe) é racional para os trabalhadores individuais ou para grupos específicos de trabalhadores?" (Ibidem, p. 14). Przeworski - coerente com sua afirmação anterior (p. 11) - assume as demonstrações de Michael Wallerstein: a resposta está na competição dos trabalhadores entre si no interior do mesmo mercado de trabalho. Przeworski acrescentaria a necessidade de se estudar o desenvolvimento individual dos membros de uma classe com os membros de outra classe. Przeworski reconhece que esta resposta é muito primíria, contudo, acredita que a crítica neoclássica deve levar a desenvolvimentos futuros muito positivos. Afirma que pouco restará da teoria marxista da ação de classe, contudo, reconhece que não há ainda respostas satisfatórias.

Ao contrário, Elster considera a crítica de Olson um desafio à teoria marxista da ação coletiva e chega mesmo a conceituar a ação coleti- 
va pela capacidade de um grupo de interesse em solucionar o problema do "carona".

A solução, ou seja, a busca dos microfundamentos que expliquem a ação coletiva, encontra-se na própria teoria dos jogos. A explicação do surgimento da participação deve tomar uma das três seguintes posições: 1) ressaltar o aspecto repetitivo da interação; 2 ) postular uma diferença entre a estrutura da recompensa material e uma que leva em conta também a interdependência das recompensas; c 3) sugerir que os agentes não se comportam de uma maneira completamente racional (Elster, 1989 b, p. 242).

O primeiro ponto procura mostrar que a cooperação é racional em casos em que o futuro faz parte das avaliações dos indivíduos: não se sabe quando acabará a interação, há um interesse sobre ganhos a longo prazo e há uma informação completa acerca das motivações dos outros agentes.

O segundo ponto demonstra que a interação continuada produz relações de confiança $\mathrm{c}$ interesse coletivo, a submissĩo do interesse egoísta ao interesse do grupo - esta visão se bascia na conclusĩo de vários estudos sobre a história das primeiras classes operárias. O terceiro ponto é inicialmente colocado sob suspeita por Elster: dever-se-ia duvidar de argumentos que invoquem a irracionalidade da ação dos indivíduos, contudo, a ação racional voltada para interesses materiais não parece ser uma resposta satisfatória para a ação do proletariado organizado - à luz do que se conhece da história operária - neste caso a versão mais plausível na opinião de Elster é: “a mudança na estrutura de preferências. Os trabalhadores tornam-se ao mesmo tempo informados e preocupados uns com os outros, através da interação contínua. A preocupação com os outros estrutura a ordenação das alternativas; e a informação sobre o outro, permite que os atores percebam a solução do jogo que se segue, 
que é o ‘jogo da garantia’ (...) a solidariedade pode substituir os incentivos materiais" (Elster, 1989, p. 188-189).

Solidariedade, confiança, preocupaçĩo com os outros, Elster parece afastar-se do individualismo metodológico e da escolla racional, contudo, logo reiteraria sua adesão inconteste aos princípios individualistas:

“Ao tratar de dar explicações, não supõe-se outra coisa que motivações egoístas e condutas racionais. O primeiro retrocesso consiste em abandonar o suposto do egoísmo e manter o da racionalidade. Só como último recurso se questiona a racionalidade dos agentes" (Elster, 1989b, p. 244).

Burawoy, na sua crítica a Elster, observa esta oscilação entre uma defesa de princípios e uma negação na prática teórica; Elster, neste livro citado, concluiria: "existem entidades supra-individuais que precedem os indivíduos na ordem de explicação" (Elster apud Burawoy, 1991, p. 101).

Para Roemer a questão da ação coletiva passa inicialmente pela busca dos fundamentos da formação de preferências, esta busca leva-o a repensar, através dos parâmetros do individualismo metodológico, o conceito de idcologia: esta será pensada como um conjunto de regras adotadas por um ator para limitar seu próprio conjunto de possibilidades (escolhas), isto é:

“(...) O estudo do assunto da formação de preferências faz necessírio postular algum aparato de metapreferências: uma pessoa possui uma variedade de perfis de preferências que

${ }^{1} \mathrm{Na}$ nota 37 , p. 243 , Elster (1989b) reafirma sua posição ao defender a prioridade "metodológica "do individualismo metodológico: "As recompensas materiais são benefícios de primeira ordem, quer dizer, têm uma necessidade lógica para que seja possível obter benefícios de segunda ordem como o altruísmo e a simpatia." 
pode 'escolher' ter e, dada a informação de seu ambiente, incluindo as restrições que enfrenta, 'elege' uma concepção de bem-estar apropriada. Haverá expectativas sobre uma pessoa pelo resto da sociedade, dado o lugar que ocupe nas forças produtivas. (...) É mais seguro dizer que a cultura seleciona as preferências de uma pessoa por ele. Mas a cultura pode ser entendida como ideologia e, se existem fundamentos racionais para a ideologia (como mencionei anteriormente), então o processo endógeno de formação de preferências pode ser visto como uma cleição racional. A formação social de um indivíduo pode explicar-se pela requisição ao mesmo tempo de que a sociedade seja entendida como uma consequência da ação de muitos indivíduos" (Roemer, 1989b, p. 227-228).

Assim, também o conceito de luta de classes é definido por Roemer a partir de uma escolha racional por parte dos trabalhadores, neste caso a escolha de um método para forçar o capital à negociação; este seria um conceito de negociação, em geral mais apropriado e mais racional que o equilíbrio competitivo.

Enfim, como os trabalhadores podem superar a problema do individualismo e compremeter-se na luta de classes? A resposta, contudo, foge aos rígidos padrões do individualismo metodológico $\mathrm{c}$ da escolha racional: a busca egoísta de vantagens materiais. Roemer fala de uma opressão comum que gera vínculos de solidariedade que, por sua vez, gera uma predisposição para a luta, através de um certo "prazer em cooperar" com os companheiros do infortúnio, visando ganhos coletivos c o prazer de se constituirem atores da história (Ibidem, p. 227-228).

Lembramos ainda a citação de Przeworki, em que Roemer determinava que em relação às classes sociais o individualismo metodológico colocava um falso problema, pois, os trabalhadores não tinham outra opção sob o capitalismo do que se organizar.

Numa avaliação preliminar, a proposta do individualismo metodológico de buscar microfundamentos tem respostas decepcionantes: no 
pior dos cenários, para Przeworski, o individualismo metodológico é, ainda, apenas uma bela promessa para o futuro; para Elster, a classe é um fator explicativo anterior ao indivíduo, $\mathrm{c}$ para Roemer não há opçĩo sob o capitalismo, para os trabalhadores além da ação coletiva. No melhor dos cenários, há a necessidade de negar a auto suficiência do individualismo metodológíco e da escolha racional para explicar a ação coletiva. Há a necessidade de agregar interesses coletivos, e valores não egoístas como "interesse pelos outros", ou fatores como "prazer da resistência”, que dificilmente se enciixam numa ação racional, etc.

\section{IV - O CONCEITO de Classe SOCIAL}

No marxismo analítico, é de John Roemer a tentativa mais séria de se reconstruir uma teoria das classes sociais sob os parâmetros fornecidos pelo individualismo metodológico. Nesta construção Roemer vai negar alguns pilares básicos que formam a base da teoria marxista das classes sociais: a tcoria da alienação $\mathrm{e} \mathrm{da} \mathrm{mais-valia} \mathrm{são} \mathrm{substituídas} \mathrm{por}$ uma teoria da exploração, a determinação estrutural e a consciência de classe são negadas em favor de uma teoria da riqueza $\mathrm{e}$ da propriedade que tem um caráter anterior à classe.

Fiel à sua adesĩo ao individualismo metodológico, Roemer define a classe social como uma escolha que visa à maximização de recursos próprios dos agentes num contexto de mercado competitivo, essa escolha se dá numa situação em que os atores envolvidos entram no jogo já com recursos materiais diferenciados por uma situação anterior onde se produziu uma diferenciação social definida pela posse ou não dos meios adequados para a produção de bens materiais - a propriedade privada dos meios de produção. Neste momento já há exploração, contudo é um tipo de exploração diferenciada da exploração tipicamente capitalis- 
ta: a exploração se dá por existir um grupo social que trabalha mais do que outro para produzir o mesmo valor-trabalho.

É importante compreender que a classe não é produto da exploração, ambas são produto da desigual distribuição da propriedade privada, contudo, esta exploração só se concretiza no mercado e não se dá pela explicação marxista tradicional da mais-valia. Para Roemer, há um tempo de trabalho total distribuído na sociedade, há atores que levam menos tempo de trabalho para produzir determinado valor enquanto outro ator leva mais tempo para produzir a mesma quantidade de valor. A exploração se concretiza quando o indivíduo transfere seu tempo de trabalho, incorporado na compra mercadoria, a quem vende esta mercadoria. A escolha racional aparece quando os indivíduos - desigualmente dotados de meios produtivos - se apresentam ao mercado, neste momento os indivíduos procuram maximizar seus recursos: vendendo ou alugando força de trabalho, trabalhando e/ou colocando.pessoas a trabalhar em sua propriedade. ${ }^{2}$

A posição de classe de um agente pode ser relacionada com a compra e venda da força de trabalho: quem compra é burguês, quem vende é proletário; pela dotação de riqueza: quem é rico é burguês, quem é pobre é proletário; pelo tempo de trabalho social: quem trabalha abaixo da média social é burguês, quem trabalha acima da média social é proletário. Numa definição política: quem é explorado é proletário, quem explora é burguês.

${ }^{2}$ Usando estas duas variáveis, comprar ou vender força de trabalho, trabalhar ou não na própria propriedade; dividida em dois blocos sociais, mundo rural e o urbano, Roemer define cinco pares de classes sociais (latifundiário/capitalista = emprega outros, não trabalha e não vende sua $\mathrm{ft}$; pequeno capitalista = camponês acomodado (?) = emprega outros, também trabalha, não vende ft.; pequeno-burguês / camponês médio = trabalha, não emprega, não vende $\mathrm{ft}$; camponês pobre/proletário misto $=$ trabalha, vende sua $\mathrm{ft}$ e não emprega; proletário/trabalhador sem-terra = não trabalha, não emprega e apenas vende) (Roemer, 1989a. p. 105). 
A teoria da exploração é fundamental no pensamento de Roemer, a partir dela a necessidade do socialismo pode adquirir nova vida. Roemer destaca a importância da teleologia marxista, contudo, critica sua característica funcionalista, destaca a necessidade de dar-lhe microfundamentos, e estes podem ser obtidos através da sua teoria da exploração. A definição de Roemer para exploração amplia o conceito para além das fronteiras do capitalismo, c pode ser usada em qualquer conjuntura histórica. Assim, pode-se definir um grupo social como explorado, se houver alguma alternativa viável à sociedade existente, lugar em que estes estariam em melhor situação da que na sua sociedade atual (processo de retirada). No caso de capitalismo isso se daria "quando uma coalizão se retira permite-se a ela levar sua participação per capita dos ativos produtivos da sociedade... a prova para a exploração capitalista equivale a igualar o acesso de cada agente à propriedade alienável da sociedade" (Roemer, 1989a., p. 123-124).

Roemer procura responder qual é o propósito de sua teoria da exploração, a resposta é "tentar explicar a luta de classes", melhor dizendo, justificar a luta de classes, dar consistência ideológica aos reclames dos trabalhadores, mostrar que existe uma saída para além do sistema capitalista - o socialismo. Entretanto, já que a desigualdade é anterior ao sistema, a apropriação desigual da propriedade privada não é produto do capitalismo, não cabendo aos trabalhadores reformarem o sistema, mas sim abandoná-lo. Além do mais, no capitalismo não há nenhuma possibilidade de deduzir a exploração de uma estrutura econômica perversa - vide a negação da mais-valia. A alegação, pelos liberais, de uma justiça social no sistema da livre-empresa é tão verdadeira como a alegação da injustiça deste pelos socialistas. Roemer relativiza os argumentos, pois para ele a pretensão de cientificidade do marxismo não existe. Este é apenas ideologia, como o é o liberalismo - uma visão 
ligada a valores -, cada um com sua ética específica. Justificar a luta dos pobres contra os ricos, este seria o objetivo do marxismo.

Assim é a postura teórica de Roemer, a construção de modelos que identifiquem as proposições éticas que existem por detrás das teorias-ideologias, é o que ele chama do "imperativo ético da teoria". E é por isso que o marxismo continua sendo válido: pela visão ética que conforma o pensamento marxista. Seu materialismo histórico, deve ser descartado pelo seu pseudo-cientificísmo c sua dialética por produzir uma teleologia funcionalista obscura.

Przeworski formula três críticas básicas à teoria de Roemer: 1) a teoria da exploração do trabalho poderia ser claborada sem nenhuma referência a classes, como fora originalmente apresentada pelo próprio Roemer. 2) Roemer, se avança em alguns pontos importantes ao introduzir microfundamentos à teoria das classes sociais, recua em três momentos dignos do típico mecanicismo da época da II Internacional: a) os sujeitos da história sĩo necessariamente e invariavelmente exploradores ou explorados, b) esses agentes colctivos necessária e invariavelmente lutam e constituem lados antagônicos em sua relação mútua, c) toda mudança histórica deve-se à luta entre exploradores e explorados.

Ora, esta visão do conflito para Roemer não só é determinista como impede que compreendamos a conjuntura atual - um tema caro a Przeworski -, ou seja, uma relação capital-trabalho que pode se desenvolver por relações de cooperação. Ou seja, 3) tudo é determinado pela dotação inicial de riqueza, o trabalhador não pode melhorar sua vida no capitalismo e portanto, sua única saída é buscar o socialismo.

$\mathrm{Na}$ busca de uma definição para a classe social, Elster negará a centralidade do conceito de exploração utilizado por Roemer, preferindo agregar a crítica weberiana - via Dahrendorf - para construir seu próprio conceito de classc. 
Elster nega ao conceito de exploração definido por Roemer uma importância tanto prática como principalmente tcórica. Elster argumenta que este conceito não permitiria compreender os estratos médios da sociedade - como a pequena-burguesia ou as burocracias - porque estes estratos compreendem tanto exploradores como explorados, também impede que compreendamos adequadamente as sutilezas de conjunturas históricas diferentes, como a diferença entre amos e capitalistas ou entre escravos e operários. Além do mais, em situações reais é difícil definir com clareza a linha que separa os exploradores dos explorados.

Já vimos que a cstrutura produtiva pode ser compreendida como uma "estrutura de possibilidades", como um limite histórico das op̧̧ões dadas aos indivíduos em determinada conjuntura histórica. A classe pode ser compreendida como uma escolha individual sc, dado determinada estrutura de recursos (dotações) os indivíduos, lançados ao mercado, são obrigados a tomar certas atitudes que os levem a maximizar o uso do que têm.

Assim, as classes são definidas não só pela estrutura de dotações, mas principalmente pelo comportamento dos agentes nas transações efetuadas no mercado:

“(...) isto nos permite propor uma definição geral de classes em termos de dotações e comportamento. As dotações inclu$\mathrm{cm}$ propriedades tangíveis, habilidades intangíveis e elementos culturais mais sutis. O comportamento se define em termos econômicos tais como trabalhar versus não trabalhar, vender versus comprar força de trabalho, emprestar versus pedir capital em empréstimo, arrendar versus alugar terra, dar versus receber ordens na administração da propriedade corporativa. Uma classe é um grupo de pessoas que, em virtude do que possuem, estão obrigados a ocupar-se nas mesmas atividades se querem fazer melhor uso de suas dotações" (Elster, 1989a, p. 172). 
Aqui cstão presentes os dois elementos weberianos incorporados por Elster: o comportamento de mercado, que determina como a dotação deve ser utilizada para a otimização; e o poder, que é fundamental para conceituar as classes sociais no mundo moderno, tanto nas grandes burocracias estatais, como nas grandes corporações de sociedade anônima. Aqui não há exploração e sim divisões sociais que são produto de divisões hierárquicas.

A proposta do marxismo analítico, a reforma do marxismo para adequá-lo ìs exigências do mundo moderno, levam Elster a repensar o papel da luta de classes nas sociedades pré-capitalistas, sociedades que teriam em comum com a nossa sociedade (pós-moderna?) a preponderância do conflito social entre grupos não classistas. Assim Elster estuda as abordagens que analisam a antiguidade clássica, o conflito patrícíos $\mathrm{x}$ plebeus, ou as revoltas escravas. Elster chega à conclusão de que a conceito de honra ou status é o mais importante para compreender os conflitos do período. Contudo, ao analisar a atuação dos escravos, Elster chega à conclusão que, se a classe não tem poder explicativo e se permanece totalmente para si, o simples fato de existir a ameaça da ação coletiva dos escravos foi um fator importante para dar forma às relações sociais (Elster, 1989a, p. 178-179). Contudo, isto não parece concluir satisfatoriamente a análise para Elster, que mantém um sentimento de que o conceito marxista das classes sociais tem um grande desafio pela frente:

"Uma olhada no mundo contemporâneo mostra que o conflito social está hoje tão longe como sempre das classes em sentido direto. Os sentimentos religiosos são a causa principal da luta no Oriente Médio, na Irlanda do Norte ou no Sri Lanka. Os conflitos raciais determinam a vida social na Afri$\mathrm{ca}$ do Sul e nos Estados Unidos. As diferenças lingüísticas mobilizam as massas na Bélgica e no Canadá. Os sentimentos nacionalistas seguem sendo fortes como sempre na maior parte do mundo. Estes sentimentos de identidade cultural fazem surgir em grande escala os atores coletivos que não pertencem às classes sociais e criam um sério problema para a teoria marxista das classes sociais" (Elster, 1989a, p. 185). 


\section{V - OS LIMITES DO INDIVIDUALISMO METODOLÓGICO}

O "manifesto programático" do marxismo analítico, apresentado no início deste trabalho- rejuvenescer o marxismo, dotando-o das ferramentas modernas do século XX para que este possa dar conta de uma conjuntura histórica mais recente e complexa - não parece se confirmar após chegarmos ao final deste trabalho, a questão que se coloca é de se saber se: se obteve uma resposta satisfatória, ou mesmo se a questão foi posta corretamente.

Ao longo deste trabalho vários pilares básicos do marxismo analítico se mostraram, no mínimo, insuficientes para dar conta do fenômeno da ação coletiva, pois afinal, este seria o objetivo básico do uso do individualismo metodológico e da escolha racional.

Como lembrou Elster, a explicação (da escolha racional) deve partir de motivações egoístas e condutas racionais, contudo a motivação egoísta não parece ser confirmada na análise de nossos autores quando estes sé voltam para o comportamento coletivo. Não custa relembrar que Roemer usa como fator explicativo da ação coletiva a solidariedade dos atores - que não é um comportamento egoísta. Fala também no "prazer em cooperar" e no "prazer da resistência", que dificilmente podem ser considerados motivações racionais.

O próprio Elster fala em relações de confiança, em interesse coletivo, na preocupação com os outros e em solidariedade. É verdade que Elster alude a uma noção de ganho ampliada - além de motivações egoístas - que se ampliaria a tudo que tenha valor para o autor em cada situação, o que incluiria até mesmo o ganho dos outros. Porém o altruísmo pode ser relacionado com um ganho individual, então a dicotomia egoísmo/altruísmo passa a não ter sentido. 
Voltemos para a questão do individualismo metodológico e sua pretensão de fornecer microfundamentos à ação coletiva. Até que ponto essa pretensão se confirma nas práticas teóricas dos marxistas analíticos?

A teoria original do individualismo metodológico, provinda da economia neoclássica, postula a formação de preferências de maneira endógena ao indivíduo, ou seja, é produto da vontade de cada indivíduo sem ser determinada por fatores externos. Contudo, a leitura dos marxistas analíticos nega a formação endógena das preferências, preferindo aludir a uma "estrutura de preferências" que seria dada historicamente, ou seja, os indivíduos escolheriam tendo como pressuposto uma estrutura de dotações (recursos) e um comportamento que tenha como objetivo otimizar estes recursos dentro de relações competitivas. Quer dizer, na estrutura de preferências, dotações e comportamentos obrigatórios, só há uma escolha individual a partir do silêncio deixado pelas estruturas acima descritas; não há uma "psicologia materialista", como disse Roemer, para decidir a escolha que o indivíduo, afinal, faz. Na realidade o que o marxismo analítico faz é analisar o impacto destas estruturas que limitam a opção de escolha do indivíduo, e não a escolha em si. Haveria, porém, a possibilidade de esta escolha ser desvendada através da "teoria dos jogos".

Contudo, a "teoria dos jogos" parece ser a menos confiável das ferramentas utilizadas pelo marxismo analítico. A primeira constatação é a de que a "teoria dos jogos" não funciona com mais de três elementos. Um conflito social onde se dê uma coalizão entre classes, assim como conflitos intergrupais, haveria dificuldade de ser analisado através desta teoria: a inclusão do Estado, por ex., como um terceiro elemento de um conflito bipolar classista, ficaria comprometido. Há de se perguntar se alguma análise do conflito classista pode eliminar um desses três elementos? 
Em outro momento, Elster fala da incapacidade da teoria dos jogos de produzir hipóteses teștáveis: existem muitos estudos sobre os jogos em si, mas não estudos das aplicações destes.

Przeworski toca na questão fundamental ao reconhecer que a "teoria dos jogos" tem uma aplicação extremamente restrita. Os trabalhos de Roemer e Elster mostram que a aplicação da "teoria dos jogos" se restringe a acontecimentos isolados e muito precisos. A aparelhagem conceitual da "teoria dos jogos" só capta fenômenos estáticos, não consegue identificar a dinâmica social.

Contudo, o marxismo tem como característica básica a capacidade de captar a mudança social sem, no entanto, perder de vista a visão da estática social (ex.: "O Capital"). Até mesmo Przeworski sustenta a idéia de que o marxismo é uma teoria da história. Este autor lembra que "cquilíbrios estáticos não dão conta da história a não ser que especifiquem porque e como ocorrem as transições entre os equilíbrios" (Przeworski, 1988, p. 6). A formulação individualista impede, segundo Roemer, de se saber como a realidade social produz seres sociais que em seguida alteram esta mesma realidade, ou seja, como indivíduos influenciados por dada realidade produzem uma nova realidade. Como a história caminha? Przeworski conclui, desanimadamente. que a aparelhagem atual do individualismo metodológico, é insatisfatória. As tarefas que uma teoria "moderna" teria que realizar seriam as seguintes:

“(...) o tratamento da formação das preferências como um produto endógeno e contínuo dos processos sociais, distinguindo catcgorias de atores por suas situações estratégicas; a utilização de conceitos historicamente específicos de equilíbrio; e, ao mesmo tempo, a explicação da história, incluindo as origens das condições, em termos das ações intençionais dos indivíduos" (Przewoski, 1988, p. 22). 
Ou seja, o individualismo metodológico deve poder incorporar a história c, portanto, a dinâmica social em seu quadro teórico. O "novo" individualismo teria como base um indivíduo compreendido como diferenciado histórica e socialmente e metido dentro de uma teia de relações sociais com outros indivíduos pertencentes a outros grupos sociais, interação esta que seria fundamental para definir sua identidade.

Contudo, a força do individualismo metodológico não está precisamente na capacidade de extirpar do marxismo sua influência hegeliana? Ao trocar a dialética por ferramentas oriundas da matemática e da lógica, o individualismo claramente optou por reduzir o marxismo à formação de modelos, de esquemas e simplificações estáticas (Roemer, 1989, p. 11). Como lembrou Przeworski: "A força do individualismo metodológico é metodológica: reside na disposição dos economistas neo-clássicos de ignorar todas as complicações que impeçam a obtenção de respostas a questões centrais" (Przcworski, 1988, p. 11).

Contudo, os marxistas analíticos continuam a apostar na capacidade do individualismo metodológico de incorporar fatores externos à teoria: de incorporar a dinâmica social e a ação coletiva, enfim de incorporar a estrutura social. A nós, porém, parece que o individualismo metodológico é uma teoria frágil que precisa criar uma redoma que a proteja da complexidade social para dar resultados. Esta teoria apresenta, em realidade, resultados pouco significativos justamente porque o seu método se destina a situações sociais simplificadas, e, portanto, nada indica que no futuro estes resultados serĩo melhores.

Argumentamos que o individualismo metodológico não pode incorporar os fatores citados acima, pois: 1) o individualismo metodológico não dá conta das ordens de preferência e da distribuição dos recursos; 2) não consegue explicar o fenômeno da ação coletiva sem recorrer a conceitos coletivistas, pois a egoísmo não explica esta ação; 3) As estruturas subjacentes não são apenas produtoras de limites, mas induzem comportamentos; não 
pode explicar as ações inconscientes da história. Seriam estas, ou seriam as ações conscientes as que são a regra na história?

Ao eliminar do marxismo suas influências hegelianas os analíticos reduziram aquele a uma teoria estática do conflito, um "positivismo radical". Retiraram do marxismo justamente seu fator de predomínio sobre outras teorias sociais: sua capacidade de compreender a sociedade a partir de conceitos funcionais, estruturais, sem perder a capacidade de incorporar a análise da dinâmica histórica.

\section{BIBLIOGRAFIA}

BURAWOY, M. "Making nonsense of Marx: O marxismo revisto pelo individualismo metodológico", in Revista Brasileira de Ciências So. ciais, $\mathrm{n}^{\circ} 15$, ano 6, fev. 1991.

ELSTER, J. "Marxismo, funcionalismo e teoria dos jogos. Argumentos em favor do individualismo metodológico". in: Lua Nova, $\mathrm{n}^{\circ}{ }^{17}$, S. Paulo, 1989.

. "Tres desafios al concepto de clase social", in J. Roemer, (comp.) El marxismo: una perspectiva analítica, Fondo de Cultura Economica, Mexico, DF, 1989a.

. "Reflexiones sobre marxismo, funcionalismo y teoria de los juegos", Fondo de Cultura Economica, Mexico, DF, 1989b.

PRZEWORSKI, A. Capitalismo e social-democracia. S. Paulo, Comp. das Letras, 1989.

. "Marxismo e escolha racional", in: Revista Brasileira de Ciências Sociais, $\mathrm{n}^{\circ}$ 6, v. 3, fev. 1988.

. "O processo de formação de classes", in: Dados - Revista de Ciências Sociais, $\mathrm{n}^{\circ}$ 2, vol. 20, 1977.

ROEMER, J. "Nuevas direcciones en la teoria marxista de las clases sociales", in: J. Roemer (comp.) El marxismo:una perspectiva analítica, Fondo de Cultura Economica, Mexico, D.F., 1989a. 
. "Marxismo de 'elección racional: algunas cuestiones de metodo y contenido", in: J. Roemer (comp.) El marxismo: una per. spectiva analitica, Fondo de Cultura Economica, Mexico, D.F., 1989b. 